Article

\title{
Haliotis discus discus Sialic Acid-Binding Lectin Reduces the Oncolytic Vaccinia Virus Induced Toxicity in a Glioblastoma Mouse Model
}

\author{
Gongchu Li *, Shengsheng Mei, Jianhong Cheng, Tao Wu and Jingjing Luo * \\ College of Life Sciences, Zhejiang Sci-Tech University, Hangzhou 310018, China; mss1053280369@163.com (S.M.); \\ cjh15067149909@163.com (J.C.); wutao0920@163.com (T.W.) \\ * Correspondence: lgc@zstu.edu.cn (G.L.); deepstoh@163.com (J.L.); Tel.: +86-571-8684-3186 (G.L. \& J.L.)
}

Received: 4 April 2018; Accepted: 25 April 2018; Published: 26 April 2018

check for updates

\begin{abstract}
Although oncolytic viruses provide attractive vehicles for cancer treatment, their adverse effects are largely ignored. In this work, rat C6 glioblastoma cells were subcutaneously xenografted into mice, and a thymidine kinase-deficient oncolytic vaccinia virus (oncoVV) induced severe toxicity in this model. However, oncoVV-HddSBL, in which a gene encoding Haliotis discus discus sialic acid-binding lectin (HddSBL) was inserted into oncoVV, significantly prolonged the survival of mice as compared to the control virus. HddSBL reduced the tumor secreted serum rat IL-2 level upregulated by oncoVV, promoted viral replication, as well as inhibited the expression of antiviral factors in C6 glioblastoma cell line. Furthermore, HddSBL downregulated the expression levels of histone $\mathrm{H} 3$ and $\mathrm{H} 4$, and upregulated histone H3R8 and H4R3 asymmetric dimethylation, confirming the effect of HddSBL on chromatin structure suggested by the transcriptome data. Our results might provide insights into the utilization of HddSBL in counteracting the adverse effects of oncolytic vaccinia virus.
\end{abstract}

Keywords: HddSBL; oncolytic vaccinia virus; glioblastoma; adverse effects

\section{Introduction}

Glioblastoma is the most common primary brain tumor and shows poor prognosis. The 2-year overall survival of glioblastoma patients is approximately $25 \%$ after current standard radiation and chemotherapy $[1,2]$. The failure of effective treatment for glioblastoma is at least partly due to the restricted permeation of drugs across the blood-brain barrier (BBB) [3,4]. Therefore, novel technologies for safer and effective clinical application are essential.

Oncolytic virotherapy is a promising treatment modality that selectively targets cancerous tissues without harming normal tissues [5]. In this strategy, virus vectors are usually designed by deleting genes important for viral replication in normal cells and inserting therapeutic genes. Through specifically infecting cancer cells, viruses amplify in the tumor and infect more cancer cells [6]. Several viruses, including measles virus (MV) [7], myxoma virus (MYXV) [8], adenovirus (Ad) [9,10], herpes simplex virus (HSV) [11-13], and vaccinia virus (VV) [14] have been utilized in glioblastoma treatment. Compared with other viral vectors, vaccinia virus offers several advantages, including large packing capacity of exogenous genes, the ability of overcoming BBB for effective tumor treatment, and rapid replication in cytoplasm, instead of integration into the host genome [15]. Oncolytic vaccinia viruses (oncoVV) have been used in clinical trials, including GLV-1h68 [16] and JX-594 [17-20]. JX-594 has a deletion of the thymidine kinase gene, and expression of human granulocyte-macrophage colony stimulating factor (GM-CSF) and $\beta$-galactosidase ( $\beta$-gal) proteins, and has showed enhanced cytotoxicity in mouse GL261 glioma cells, compared with reovirus or VSV $\Delta$ M51. However, the adverse effects of oncolytic viruses have been largely ignored. 
Lectins, distributed ubiquitously in plants, animals, and fungi, are highly diverse carbohydrate-binding proteins, which selectively recognize and bind distinct sugar-containing receptors on cellular surfaces [21,22]. Regarding their biochemical properties, lectins hold not only potential for cancer diagnosis and prognosis, but also show great potential for application in cancer therapy, through activating apoptotic- or autophagic-related signaling pathways. Previous studies have showed the anticancer potential of various lectins, including galectin [23,24], mistletoe lectin [25], concanavalin A [26], and MytiLec [27-30]. In our previous work, we have demonstrated the anticancer efficiency of adenovirus-mediated lectin expression, including mannose-binding lectin from Pinellia pedatisecta agglutinin (PPA) [31], Ulva pertusa lectin 1 [32], Strongylocentrotus purpuratus rhamnose binding lectin (SpRBL), Dicentrarchus labrax fucose binding lectin (DIFBL) [33], and Haliotis discus discus sialic acid-binding lectin (HddSBL), which elicited significant in vitro and in vivo suppressive effects on a variety of tumor cells. HddSBL exogenously expressed from adenovirus vectors has shown significant growth inhibition on hepatocellular carcinoma Hep3B cells, colon carcinoma SW480 cells, and lung cancer cell lines A549 and H1299 [34].

Here, we show that an oncoVV with the deletion of thymidine kinase gene was toxic to mice subcutaneously xenografted with rat C6 glioblastoma cells. Interestingly, the survival of C6 glioblastoma xenograft mice was prolonged by oncoVV harboring HddSBL (oncoVV-HddSBL) as compared to the control oncoVV virus. We further showed that HddSBL downregulated serum rat interleukin-2 (IL-2) levels, inhibited the production of intracellular antiviral factors, promoted viral replication, and influenced histone methylation.

\section{Results}

\subsection{HddSBL Reduced the Toxicity of OncoVV in a Subcutaneous C6 Glioblastoma Xenograft Mouse Model}

We first assessed the efficacy of oncoVV and oncoVV-HddSBL in a subcutaneous glioblastoma xenograft model. Rat C6 glioblastoma xenografts were grown in the right flank of athymic BALB/c nude mice. The xenograft model was established by day 10 and the tumor volume reached about $100 \mathrm{~mm}^{3}$, followed by intraperitoneal injection of PBS, oncoVV, or oncoVV-HddSBL. As shown in Figure $1 \mathrm{a}$, oncoVV exhibited severe toxicity. However, the survival of the oncoVV-HddSBL group was significantly prolonged as compared to the oncoVV group. Our unpublished data have demonstrated the safety of this control oncoVV virus to several other tumor-bearing mouse models, indicating that the toxicity of oncoVV shown here was induced through acting on C6 tumors. Therefore, we further investigated the effect of oncoVV-HddSBL on C6 xenografts, as well as C6 tumor cells.

\subsection{OncoVV-HddSBL Reduced Tumor Secretion of Rat IL-2}

We then investigated the potential mechanisms underlying prolonged survival of mice by oncoVV-HddSBL. After 15 days of the first injection of VV, secretion of rat IL-2 in the xenograft tumors was measured by ELISA assay (Figure 1b). Compared to the PBS control, the oncoVV enhanced the secretion of IL-2 $(p<0.05)$, while the oncoVV-HddSBL significantly reduced the secretion of IL-2 compared to the oncoVV group $(p<0.05)$. The transcription levels of rat IL-2 in vitro were investigated by RT-PCR analysis after C6 cells were infected with 5 multiplicity of infection (MOI) of VVs (Figure 1c), which was consistent with ELISA assay results. Furthermore, the activity of inflammation related transcription factors nuclear factor- $\mathrm{KB}$ (NF- $\mathrm{KB}$ ) and activator protein-1 (AP-1) was upregulated in oncoVV-HddSBL-treated C6 cells, as compared to PBS and oncoVV controls (Figure 2). Taken together, our data suggested that the prolonged survival of $\mathrm{C} 6$ mice by oncoVV-HddSBL might be due to the significant reduction of IL-2 secretion from tumor cells, whereas the activation of inflammatory transcription factors NF- $\mathrm{kB}$ and $\mathrm{AP}-1$ limited this effect. 
a
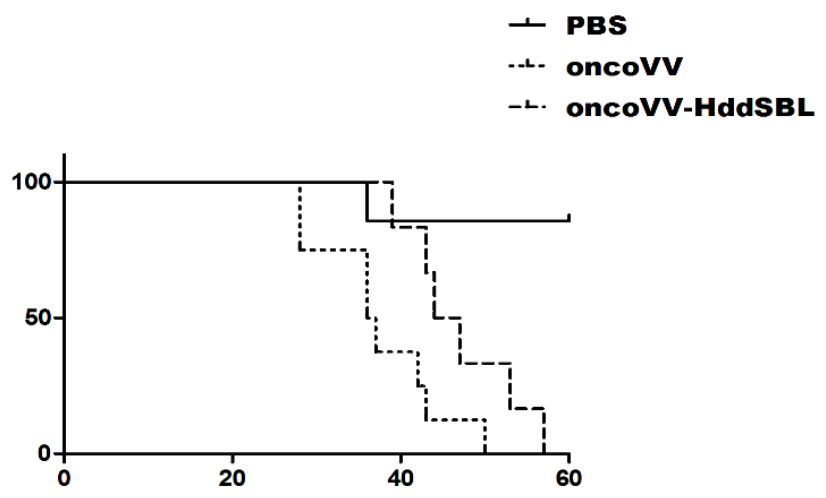

b

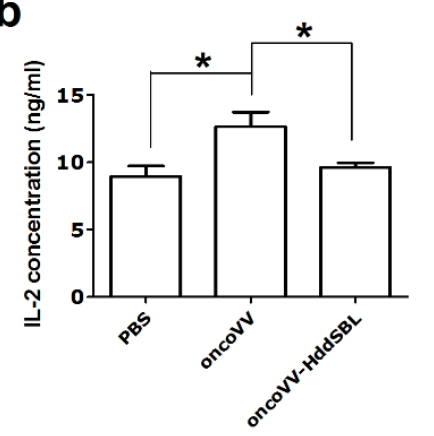

C

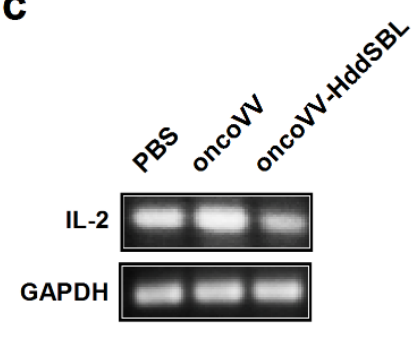

Figure 1. The oncolytic vaccinia virus (oncoVV)-Haliotis discus discus sialic acid-binding lectin (HddSBL) reduced toxicity and prolonged survival of mice compared to the oncoVV. (a) Kaplan-Meier survival curves of C6 glioblastoma xenograft mouse model. (b) ELISA assay of IL-2 secretion. (c) Reverse transcriptase-polymerase chain reaction (RT-PCR) analysis of rat IL-2 at mRNA levels.

a

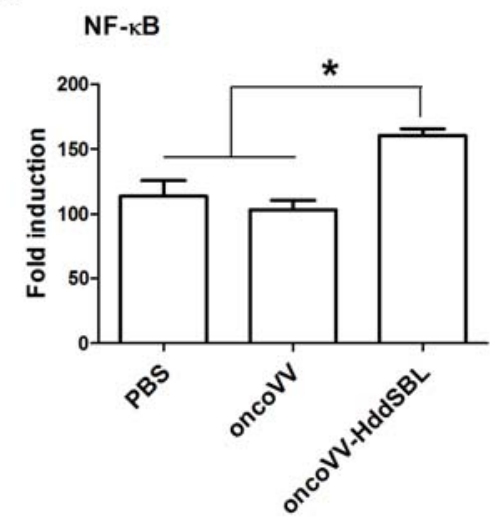

b

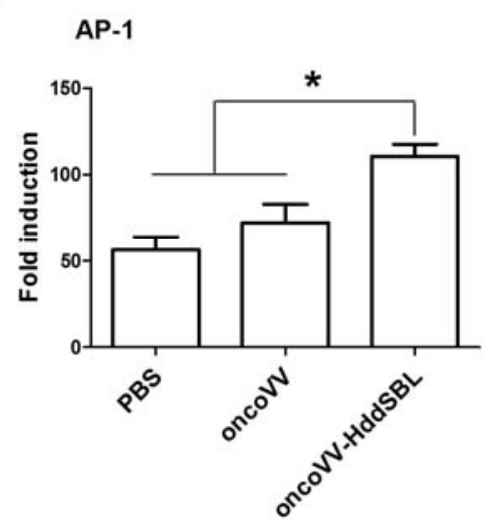

Figure 2. The effects of oncoVV and oncoVV-HddSBL on (a) NF- $\mathrm{kB}$ and (b) AP-1 activation in C6 glioblastoma cells using NF- $\mathrm{kB}$ or AP-1 reporter assay. ${ }^{*} p<0.05$.

\subsection{Virus Replication in Rat C6 Glioblastoma Cells}

After rat C6 glioblastoma cells were infected with 5 MOI oncoVV or oncoVV-HddSBL for $36 \mathrm{~h}$, total RNA was extracted from cells, differentially expressed genes were screened, and transcriptome sequencing analysis was carried out. The result of gene enrichment analysis is shown in Figure 3. Then, the representing differentially expressed genes were selected and shown in Figure 4, including several factors related to intracellular viral controlling. Therefore, $\mathrm{C} 6$ glioblastoma cells were 
then infected with $5 \mathrm{MOI}$ oncoVV or oncoVV-HddSBL, and virus replication was investigated at $24 \mathrm{~h}$ and $36 \mathrm{~h}$. The results showed that the oncoVV-HddSBL was nearly 2-fold higher at $24 \mathrm{~h}$ and 7 -fold higher at $36 \mathrm{~h}$ than that of control oncoVV (Figure 5a). We then investigated the transcription levels of antiviral factors IFIT2 (interferon-induced protein with tetratricopeptide repeats 2), IFIT3, and DDX58 (DEAD-box helicase 58) by RT-PCR. The transcription of IFIT2, IFIT3, and DDX58 was upregulated in oncoVV group, while the oncoVV-HddSBL dramatically decreased their levels as compared to oncoVV treatment (Figure 5b), which was consistent with the transcriptome data shown in Figure 4.

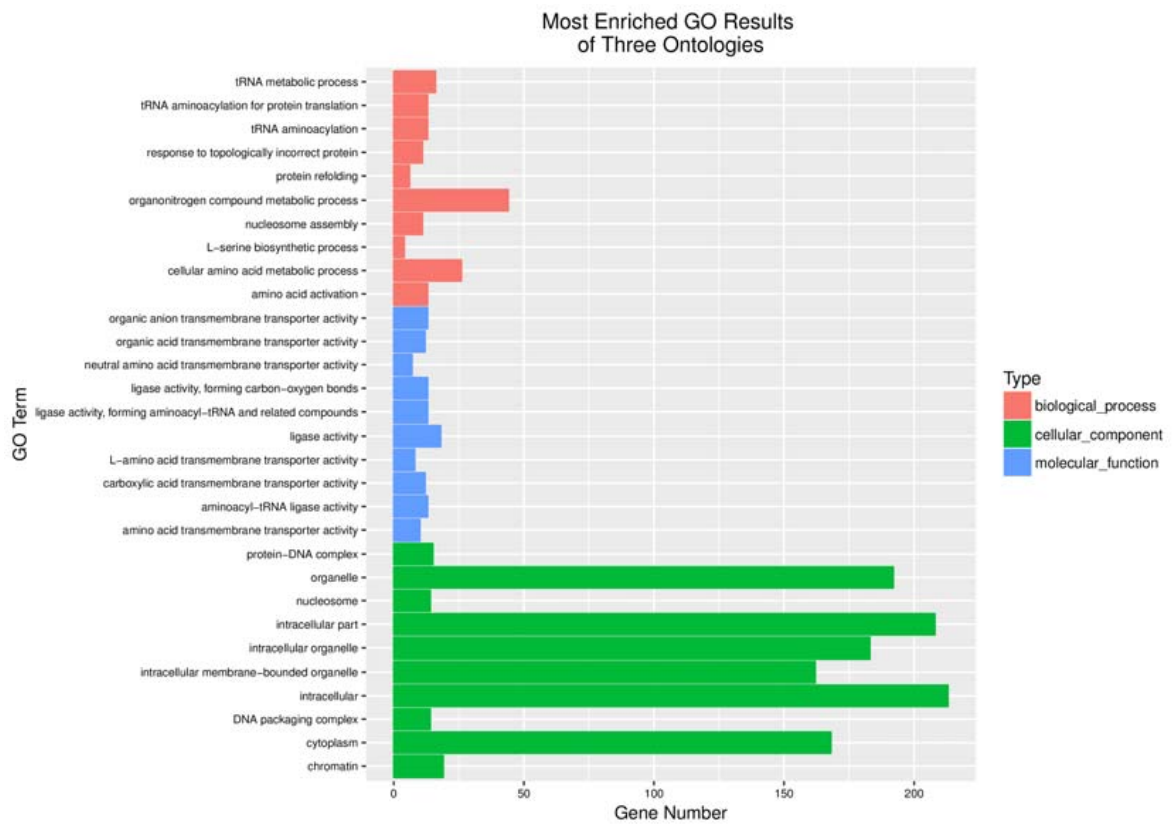

Figure 3. Functional categorization of up-regulated genes based on gene ontology (GO) annotations between oncoVV and oncoVV-HddSBL treatments.

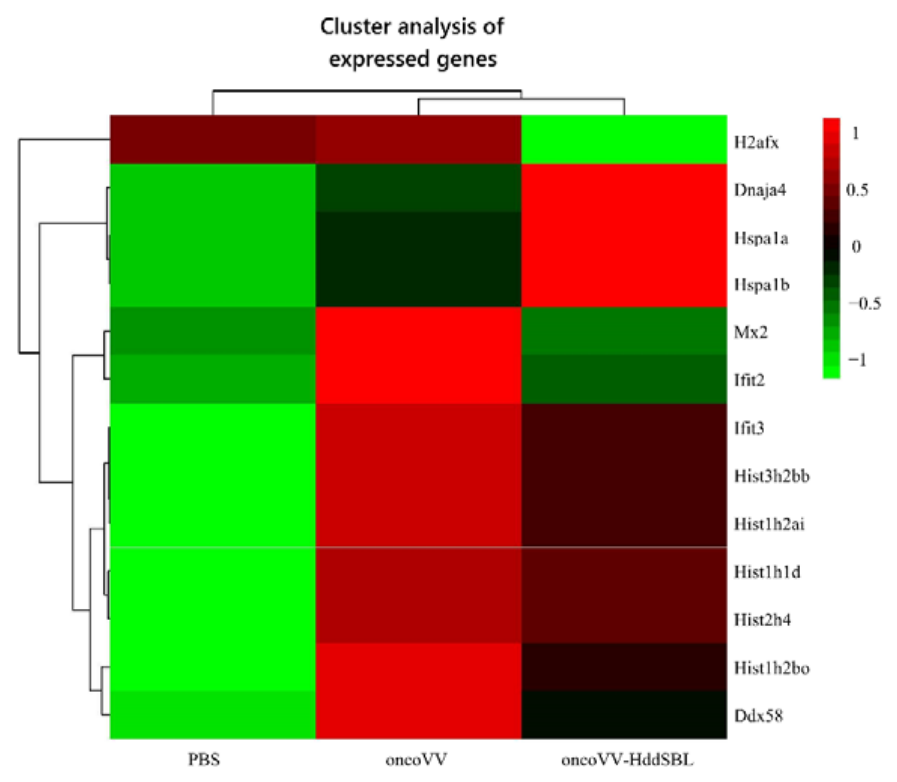

Figure 4. Screening and functional analysis of differentially expressed genes after treatment of C6 glioblastoma cells with PBS, oncoVV (5 MOI), and oncoVV-HddSBL (5 MOI) for $36 \mathrm{~h}$. Scale bar is in log10. 
a

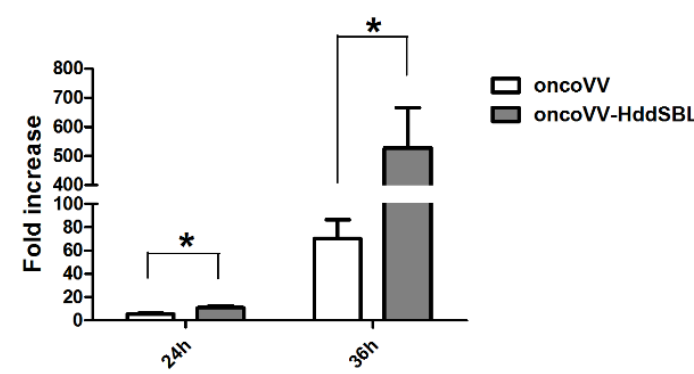

b

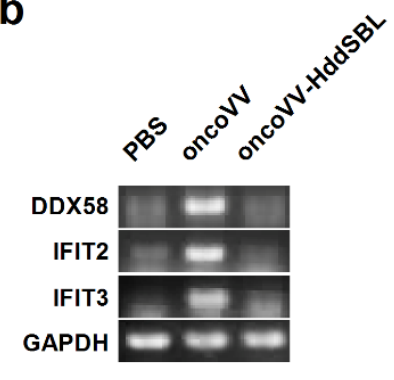

Figure 5. HddSBL promoted viral replication and inhibited antiviral factors in C6 glioblastoma cells. (a) Viral replication in C6 glioblastoma cells; (b) RT-PCR for mRNA levels of antiviral genes. ${ }^{*} p<0.05$.

\subsection{The Effect of HddSBL on Histone Modification}

As shown in our transcriptome data, among the most significant categories, we found terms related to chromatin structure such as "nucleosome", "protein-DNA complex", "DNA packaging complex", and "chromatin". We then verified the effect of HddSBL on chromatin structure regulation. The oncoVV-HddSBL treatment showed significant downregulation of histone $\mathrm{H} 3$ and histone $\mathrm{H} 4$, and upregulation of histone $\mathrm{H} 3 \mathrm{Arg} 8$ asymmetric methylation (H3R8me2a), and histone $\mathrm{H} 4 \mathrm{Arg} 3$ asymmetric methylation (H4R3me2a) in C6 glioblastoma cells (Figure 6). Our results indicated that HddSBL influenced histone modification, which was consistent with the result of transcriptome data. Furthermore, the expression of FLAG-tagged HddSBL was also verified by Western blot with an antibody against FLAG.

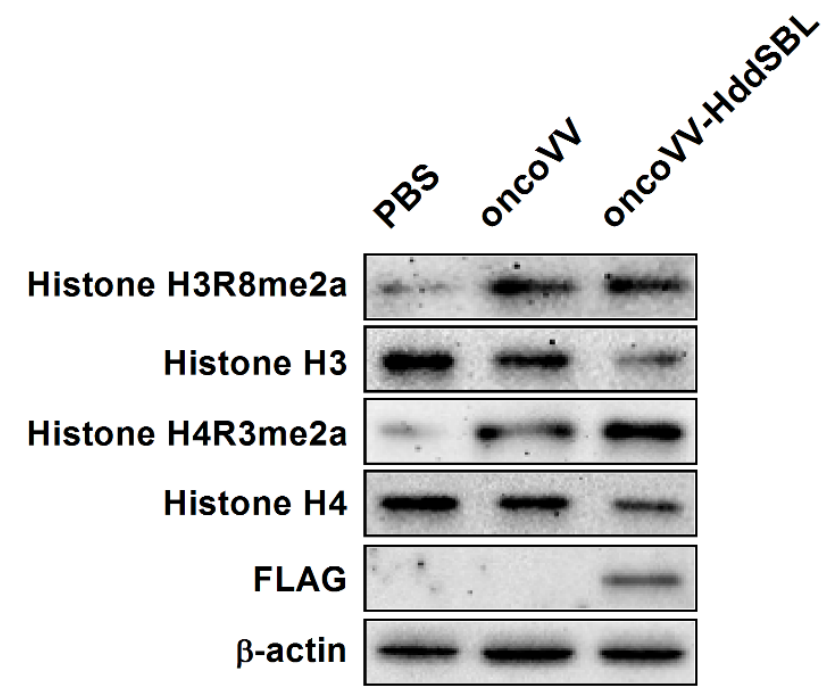

Figure 6. The effect of oncoVV-HddSBL on histone modification. C6 glioblastoma cells were treated with PBS, 5 MOI of oncoVV or oncoVV-HddSBL, and histone H3, H4, H3R8, and H4R3 asymmetric dimethylation levels, as well as the expression of FLAG-tagged HddSBL were analyzed by Western blot.

\section{Discussion}

Oncolytic viruses provide an alternative tool for cancer treatment. The transgenes can be integrated into recombinant vectors to form tumor-selective, multi-mechanistic antitumor agents. Deletion of viral genes that are necessary for replication in normal cells greatly enhances cancer cell-specific replication of oncolytic viruses [35]. Their oncolytic effects can be enhanced through the insertion of foreign antitumor genes $[36,37]$. Due to the large packing capacity of exogenous genes, VV is particularly attractive as a potential therapeutic agent for the treatment of malignant tumors. However, the adverse effects of 
VV have been ignored in many studies. In this work, we demonstrated the potential for lectin HddSBL carried by oncoVV for reducing the oncoVV-induced severe toxicity in treatment of glioblastoma.

The interferons (IFNs) induced protein with tetratricopeptide repeats (IFITs) family participates in diverse processes in response to viral infection [38]. IFIT2 is located in microtubules, and plays an important role in cell proliferation and microtubule dynamics. IFIT3 is located in the cytoplasm and mitochondria, and is also recognized as an antiviral protein. Our study showed that HddSBL inhibits the oncoVV-induced antiviral factors, which favored oncoVV replication in $\mathrm{C} 6$ cells. In addition, previous studies have demonstrated that a high dose of IL-2 led to substantial acute toxicity $[39,40]$. In our study, a decrease in IL-2 secretion was shown to be associated with prolonged survival of oncoVV-HddSBL-treated mice. Thus, our results have suggested that HddSBL affected multiple signaling pathways related to immune responses induced by oncoVV. Therefore, further investigations into the underlying mechanism may help to develop oncoVV-HddSBL into an agent for controlling oncoVV toxicity.

\section{Materials and Methods}

\subsection{Cell Culture and Production of oncoVV-HddSBL}

Rat C6 glioblastoma cells and human embryonic kidney cells HEK293A were obtained from American Type Culture Collection (Rockville, MD, USA) and were cultured in DMEM medium (Gibco, Thermo Fisher Scientific, Waltham, MA, USA) with 10\% fetal bovine serum (FBS, Gibco). The gene encoding Haliotis discus discus sialic acid-binding lectin (HddSBL, GenBank accession No. EF103404) was integrated into the plasmid pCB with a thymidine kinase (TK) gene deletion to form pCB-HddSBL. The plasmid was cotransfected into HEK293A cells using Effectene Transfection Reagent (Qiagen, Hilden, Germany) with WR vaccinia virus to generate oncoVV-HddSBL through homologous recombination. OncoVV without transgene has been constructed previously as control virus. The viruses were amplified in HEK293A cells and purified by sucrose-gradient ultracentrifugation.

\subsection{Subcutaneous C6 Glioblastoma Xenograft Mouse Model}

Mice were cared for in accordance with the Guide for the Care and Use of Laboratory Animals. Xenograft tumors (rat C6 glioblastoma) were established by injecting $1 \times 10^{5}$ cells in $100 \mu \mathrm{L}$ PBS subcutaneously into the right flank of 4-5 weeks old female BALB/c nude mice (Shanghai Slack Animal Laboratory, China), with each group consisting of 7 mice. Treatment started when tumor size reached about $100 \mathrm{~mm}^{3}$. OncoVV or oncoVV-HddSBL was injected intraperitoneally at $1 \times 10^{7}$ plaque-forming units (pfu) in $100 \mu \mathrm{L}$ PBS twice. Control animals received intraperitoneal injections of PBS. The survival of mice was monitored every day.

\subsection{ELISA Assay for IL-2 Secretion}

The secretion of IL-2 in tumors was determined by ELISA assay using the Rat IL-2 ELISA Kit (Multi Science, CA, USA) according to the manufacturer's instructions. Briefly, mice serum samples were obtained from tumor veins after 15 days of the first injection of VVs. Serum samples were incubated with anti-Rat IL-2 antibody in ELISA plate for $1.5 \mathrm{~h}$ at room temperature. Then, the samples were washed 6 times with washing buffer and incubated with streptavidin-HRP for $0.5 \mathrm{~h}$ at room temperature. After washing three times in washing buffer, samples were incubated with substrate solution for $30 \mathrm{~min}$ at room temperature. The absorbance of the sample at $450 \mathrm{~nm}$ was read on an absorption spectrophotometer after the addition of stop solution.

\subsection{Screening and Functional Analysis of Differentially Expressed Genes and Analysis of Gene Enrichment}

Rat C6 glioblastoma cells were plated at $5 \times 10^{6}$ in $10 \mathrm{~cm}$ dishes $(n=3)$. After culture overnight, cells were infected at a multiplicity of infection (MOI) of 5 with oncoVV or oncoVV-HddSBL for $36 \mathrm{~h}$. PBS served as the negative control. Total RNA was extracted from cells using TRIzol reagent (Invitrogen, Waltham, 
MA, USA). Differentially expressed genes were screened, and the transcriptome sequencing and analysis was carried out by Vazyme Biotech Co., Ltd. (Nanjing, China).

\subsection{Virus Replication Assay}

To determine the viral replication capacity of VVs in C6 glioblastoma cells, cells were plated on 24-well plates at $1 \times 10^{5}$ cells per well one day before treatment with viruses. Then, cells were infected with oncoVV or oncoVV-HddSBL at a MOI of 2 for $2 \mathrm{~h}, 24 \mathrm{~h}$, and $36 \mathrm{~h}$. Cells and culture medium were collected and lysed with three cycles of freeze-thawing at the time interval indicated. Then, the supernatants were collected by centrifugation, and viral titers were measured through tissue culture infectious dose (TCID50) assay.

\subsection{Semi-Quantitative Reverse Transcription Polymerase Chain Reaction (RT-PCR) Analysis}

C6 glioblastoma cells were seeded at a density of $8 \times 10^{4}$ cells per well on the 24 well plate. MOI of 5 oncoVV or oncoVV-HddSBL were added, respectively, the next day. Total RNA was extracted from cells using TRIzol reagent (Invitrogen) according to the manufacturer's instructions. The total RNA was then reverse transcribed into cDNA using reverse transcription kit (TOYOBO). Primer sequences for GAPDH used were $5^{\prime}$-ATGGTGAAGGTCGGTGTGAAC- $3^{\prime}$ (sense) and 5'-ATGGGTTTCCCGTTGATGAC- ${ }^{\prime}$ (antisense). The PCR primers for rat IL-2 were $5^{\prime}$-ATGTACAGCATGCAGCTCGC-3' (sense) and $5^{\prime}$-GATATTTCAATTCTGTGGCC-3' (antisense). The PCR primers for IFIT3 were $5^{\prime}$-CCATTGCCATGTACCGCCTA-3' (sense) and $5^{\prime}$-GCATCTTCAACCAACCGCTC- $3^{\prime}$ (antisense). The PCR primers for IFIT2 were 5'-ATGCCACTTCACCTGGAACC-3' (sense) and $5^{\prime}$-CTTCGGCTTCCCCTAAGCAT-3' (antisense). The PCR primers for DDX58 were 5'-TGCAAGGCGCTCTTTCTGTA-3' (sense) and 5'-CAAAGCCTTCAAACCTCCGC-3' (antisense).

\subsection{Western Blot Analysis}

Cells were plated at $1 \times 10^{6}$ in $60 \mathrm{~mm}$ dishes. After infected with MOI of 5 oncoVV or oncoVV-HddSBL respectively, cells were harvested in ice-cold cell lysis buffer (Beyotime Institute of Biotechnology, Shanghai, China). The extracts were then subjected to SDS-PAGE and transferred to nitrocellulose membranes. The membranes were subsequently blocked with $5 \%$ bovine serum albumin for $2 \mathrm{~h}$ at room temperature and incubated at $4{ }^{\circ} \mathrm{C}$ overnight with corresponding antibodies. After washing with TBST buffer (0.01 M Tris-buffered saline with $0.1 \%$ Tween-20), the membrane was incubated with HRP-conjugated secondary antibodies for $1 \mathrm{~h}$ at room temperature. After washing with TBS buffer, membranes were exposed to the Tanon 5500 chemiluminescence image system (Tanon Inc., Shanghai, China). Anti-histone H3, anti-histone H4, anti-flag, and anti- $\beta$-actin antibodies were obtained from Cell Signaling Technology Inc. (Danvers, MA, USA). Histone H3 dimethyl Arg8 asymmetric and Histone H4 dimethyl Arg3 asymmetric antibodies were purchased from Active Motif (Carlsbad, CA, USA).

\subsection{Reporter Assay}

To determine the impact of viruses on NF- $\mathrm{kB}$ and AP-1 activation, we co-transfected rat C6 glioblastoma cells with the Renilla luciferase control plasmid together with reporter plasmids coding for firefly luciferase gene downstream of NF- $\mathrm{kB}$ or AP-1 binding sites, followed by treatment of $\mathrm{C} 6$ glioblastoma cells with PBS, oncoVV (MOI 5), or oncoVV-HddSBL (MOI 5) for $24 \mathrm{~h}(n=3)$. The ratio of firefly to Renilla luciferase activity was measured using a dual-luciferase assay system (GeneCopoeia, Inc., Rockville, MD, USA).

\subsection{Statistical Analysis}

Statistical significance was determined with Student's $t$-test. $p<0.05$ was considered significant. 


\section{Conclusions}

In this work, a subcutaneous C6 glioblastoma xenograft model was established, and oncoVV-HddSBL exhibited the ability to prolong the survival of tumor-bearing mice as compared to the control virus oncoVV. The tumor secreted serum IL-2 level was downregulated in the oncoVV-HddSBL group compared to the oncoVV group. Furthermore, oncoVV-HddSBL exhibited higher viral replication capability, and intracellular antiviral factors, including DDX58, IFIT2, and IFIT3, induced by oncoVV, were dramatically decreased by HddSBL. HddSBL was also shown to modulate the histone modification and may influence the chromatin structure. Taken together, HddSBL reduced the oncoVV induced toxicity in a C6 glioblastoma mouse model by affecting multiple signaling pathways.

Author Contributions: G.L. conceived and designed the experiments; G.L., S.M., J.C., and T.W. performed the experiments; G.L. analyzed the data; G.L. and J.L. wrote the paper.

Funding: This work was supported by National Natural Science Foundation of China grant 81572986, Zhejiang Provincial Natural Science Foundation grant LZ16D060002, and Zhejiang Provincial Top Key Discipline of Biology.

Conflicts of Interest: The authors declare no conflict of interest.

\section{References}

1. Van Tellingen, O.; Yetkin-Arik, B.; de Gooijer, M.C.; Wesseling, P.; Wurdinger, T.; de Vries, H.E. Overcoming the blood-brain tumor barrier for effective glioblastoma treatment. Drug Resist. Update 2015, 19, 1-12. [CrossRef] [PubMed]

2. Tanaka, S.; Louis, D.N.; Curry, W.T.; Batchelor, T.T.; Dietrich, J. Diagnostic and therapeutic avenues for glioblastoma: No longer a dead end? Nat. Rev. Clin. Oncol. 2013, 10, 14-26. [CrossRef] [PubMed]

3. Kim, S.S.; Harford, J.B.; Pirollo, K.F.; Chang, E.H. Effective treatment of glioblastoma requires crossing the blood-brain barrier and targeting tumors including cancer stem cells: The promise of nanomedicine. Biochem. Biophys. Res. Commun. 2015, 468, 485-489. [CrossRef] [PubMed]

4. Jue, T.R.; McDonald, K.L. The challenges associated with molecular targeted therapies for glioblastoma. J. Neuro-Oncol. 2016, 127, 427-434. [CrossRef] [PubMed]

5. Russell, S.J.; Peng, K.W.; Bell, J.C. Oncolytic virotherapy. Nat. Biotechnol. 2012, 30, 658-670. [CrossRef] [PubMed]

6. Fukuhara, H.; Ino, Y.; Todo, T. Oncolytic virus therapy: A new era of cancer treatment at dawn. Cancer Sci. 2016, 107, 1373-1379. [CrossRef] [PubMed]

7. Allen, C.; Opyrchal, M.; Aderca, I.; Schroeder, M.A.; Sarkaria, J.N.; Domingo, E.; Federspiel, M.J.; Galanis, E. Oncolytic measles virus strains have significant antitumor activity against glioma stem cells. Gene Ther. 2013, 20, 444-449. [CrossRef] [PubMed]

8. Zemp, F.J.; McKenzie, B.A.; Lun, X.; Reilly, K.M.; McFadden, G.; Yong, V.W.; Forsyth, P.A. Cellular factors promoting resistance to effective treatment of glioma with oncolytic myxoma virus. Cancer Res. 2014, 74, 7260-7273. [CrossRef] [PubMed]

9. Oh, E.; Hong, J.; Kwon, O.J.; Yun, C.O. A hypoxia- and telomerase-responsive oncolytic adenovirus expressing secretable trimeric TRAIL triggers tumour-specific apoptosis and promotes viral dispersion in TRAIL-resistant glioblastoma. Sci. Rep. 2018, 8, 1420. [CrossRef] [PubMed]

10. Shimazu, Y.; Kurozumi, K.; Ichikawa, T.; Fujii, K.; Onishi, M.; Ishida, J.; Oka, T.; Watanabe, M.; Nasu, Y.; Kumon, H.; et al. Integrin antagonist augments the therapeutic effect of adenovirus-mediated REIC/Dkk-3 gene therapy for malignant glioma. Gene Ther. 2015, 22, 146-154. [CrossRef] [PubMed]

11. Duebgen, M.; Martinez-Quintanilla, J.; Tamura, K.; Hingtgen, S.; Redjal, N.; Wakimoto, H.; Shah, K. Stem cells loaded with multimechanistic oncolytic herpes simplex virus variants for brain tumor therapy. J. Natl. Cancer Inst. 2014, 106, dju090. [CrossRef] [PubMed]

12. Alvarez-Breckenridge, C.A.; Choi, B.D.; Suryadevara, C.M.; Chiocca, A. Potentiating oncolytic viral therapy through an understanding of the initial immune responses to oncolytic viral infection. Curr. Opin. Virol. 2015, 13, 25-32. [CrossRef] [PubMed]

13. Meisen, W.H.; Wohleb, E.S.; Jaime-Ramirez, A.C.; Bolyard, C.; Yoo, J.Y.; Russell, L.; Hardcastle, J.; Dubin, S.; Muili, K.; Yu, J.H.; et al. The Impact of Macrophage- and Microglia-Secreted TNF alpha on Oncolytic HSV-1 
Therapy in the Glioblastoma Tumor Microenvironment. Clin. Cancer Res. 2015, 21, 3274-3285. [CrossRef] [PubMed]

14. Kober, C.; Rohn, S.; Weibel, S.; Geissinger, U.; Chen, N.H.G.; Szalay, A.A. Microglia and astrocytes attenuate the replication of the oncolytic vaccinia virus LIVP 1.1.1 in murine GL261 gliomas by acting as vaccinia virus traps. J. Transl. Med. 2015, 13, 216. [CrossRef] [PubMed]

15. Advani, S.J.; Buckel, L.; Chen, N.G.; Scanderbeg, D.J.; Geissinger, U.; Zhang, Q.; Yu, Y.A.; Aguilar, R.J.; Mundt, A.J.; Szalay, A.A. Preferential Replication of Systemically Delivered Oncolytic Vaccinia Virus in Focally Irradiated Glioma Xenografts. Clin. Cancer Res. 2012, 18, 2579-2590. [CrossRef] [PubMed]

16. Mell, L.K.; Brumund, K.T.; Daniels, G.A.; Advani, S.J.; Zakeri, K.; Wright, M.E.; Onyeama, S.J.; Weisman, R.A.; Sanghvi, P.R.; Martin, P.J.; et al. Phase I Trial of Intravenous Oncolytic Vaccinia Virus (GL-ONC1) with Cisplatin and Radiotherapy in Patients with Locoregionally Advanced Head and Neck Carcinoma. Clin. Cancer Res. 2017, 23, 5696-5702. [CrossRef] [PubMed]

17. Breitbach, C.J.; Burke, J.; Jonker, D.; Stephenson, J.; Haas, A.R.; Chow, L.Q.M.; Nieva, J.; Hwang, T.H.; Moon, A.; Patt, R.; et al. Intravenous delivery of a multi-mechanistic cancer-targeted oncolytic poxvirus in humans. Nature 2011, 477, 99-102. [CrossRef] [PubMed]

18. Murphy, A.M.; Rabkin, S.D. Current status of gene therapy for brain tumors. Transl. Res. 2013, 161, 339-354. [CrossRef] [PubMed]

19. Hwang, T.H.; Moon, A.; Burke, J.; Ribas, A.; Stephenson, J.; Breitbach, C.J.; Daneshmand, M.; De Silva, N.; Parato, K.; Diallo, J.S.; et al. A Mechanistic Proof-of-concept Clinical Trial with JX-594, a Targeted Multi-mechanistic Oncolytic Poxvirus, in Patients with Metastatic Melanoma. Mol. Ther. 2011, 19, 1913-1922. [CrossRef] [PubMed]

20. Parato, K.A.; Breitbach, C.J.; Le Boeuf, F.; Wang, J.H.; Storbeck, C.; Ilkow, C.; Diallo, J.S.; Falls, T.; Burns, J.; Garcia, V.; et al. The Oncolytic Poxvirus JX-594 Selectively Replicates in and Destroys Cancer Cells Driven by Genetic Pathways Commonly Activated in Cancers. Mol. Ther. 2012, 20, 749-758. [CrossRef] [PubMed]

21. Jiang, Q.L.; Zhang, S.; Tian, M.; Zhang, S.Y.; Xie, T.; Chen, D.Y.; Chen, Y.J.; He, J.; Liu, J.; Ouyang, L.; et al. Plant lectins, from ancient sugar-binding proteins to emerging anti-cancer drugs in apoptosis and autophagy. Cell Prolif. 2015, 48, 17-28. [CrossRef] [PubMed]

22. Hyun, J.Y.; Park, C.W.; Liu, Y.; Kwon, D.; Park, S.H.; Park, S.; Pai, J.; Shin, I. Carbohydrate Analogue Microarrays for Identification of Lectin-Selective Ligands. Chembiochem 2017, 18, 1077-1082. [CrossRef] [PubMed]

23. Thijssen, V.L.; Heusschen, R.; Caers, J.; Griffioen, A.W. Galectin expression in cancer diagnosis and prognosis: A systematic review. BBA-Rev. Cancer 2015, 1855, 235-247. [CrossRef] [PubMed]

24. Yau, T.; Dan, X.L.; Ng, C.C.W.; Ng, T.B. Lectins with Potential for Anti-Cancer Therapy. Molecules 2015, 20, 3791-3810. [CrossRef] [PubMed]

25. Han, S.Y.; Hong, C.E.; Kim, H.G.; Lyu, S.Y. Anti-cancer effects of enteric-coated polymers containing mistletoe lectin in murine melanoma cells in vitro and in vivo. Mol. Cell. Biochem. 2015, 408, 73-87. [CrossRef] [PubMed]

26. Chang, C.P.; Yang, M.C.; Liu, H.S.; Lin, Y.S.; Lei, H.Y. Concanavalin A induces autophagy in hepatoma cells and has a therapeutic effect in a murine in situ hepatoma model. Hepatology 2007, 45, 286-296. [CrossRef] [PubMed]

27. Terada, D.; Kawai, F.; Noguchi, H.; Unzai, S.; Hasan, I.; Fujii, Y.; Park, S.Y.; Ozeki, Y.; Tame, J.R.H. Crystal structure of MytiLec, a galactose-binding lectin from the mussel Mytilus galloprovincialis with cytotoxicity against certain cancer cell types. Sci. Rep. UK 2016, 6, 28344. [CrossRef] [PubMed]

28. Hasan, I.; Gerdol, M.; Fujii, Y.; Rajia, S.; Koide, Y.; Yamamoto, D.; Kawsar, S.M.A.; Ozeki, Y. cDNA and Gene Structure of MytiLec-1, A Bacteriostatic R-Type Lectin from the Mediterranean Mussel (Mytilus galloprovincialis). Mar. Drugs 2016, 14, 92. [CrossRef] [PubMed]

29. Hasan, I.; Sugawara, S.; Fujii, Y.; Koide, Y.; Terada, D.; Iimura, N.; Fujiwara, T.; Takahashi, K.G.; Kojima, N.; Rajia, S.; et al. MytiLec, a Mussel R-Type Lectin, Interacts with Surface Glycan Gb3 on Burkitt's Lymphoma Cells to Trigger Apoptosis through Multiple Pathways. Mar. Drugs 2015, 13, 7377-7389. [CrossRef] [PubMed]

30. Fujii, Y.; Dohmae, N.; Takio, K.; Kawsar, S.M.A.; Matsumoto, R.; Hasan, I.; Koide, Y.; Kanaly, R.A.; Yasumitsu, H.; Ogawa, Y.; et al. A Lectin from the Mussel Mytilus galloprovincialis Has a Highly Novel Primary Structure and Induces Glycan-mediated Cytotoxicity of Globotriaosylceramide-expressing Lymphoma Cells. J. Biol. Chem. 2012, 287, 44772-44783. [CrossRef] [PubMed] 
31. Li, G.; Li, X.; Wu, H.; Yang, X.; Zhang, Y.; Chen, L.; Wu, X.; Cui, L.; Wu, L.; Luo, J.; et al. CD123 targeting oncolytic adenoviruses suppress acute myeloid leukemia cell proliferation in vitro and in vivo. Blood Cancer J. 2014, 4, e194. [CrossRef] [PubMed]

32. Li, G.C.; Zhao, Z.Z.; Wu, B.B.; Su, Q.S.; Wu, L.Q.; Yang, X.Y.; Chen, J. Ulva pertusa lectin 1 delivery through adenovirus vector affects multiple signaling pathways in cancer cells. Glycoconj. J. 2017, 34, 489-498. [CrossRef] [PubMed]

33. Wu, L.Q.; Yang, X.Y.; Duan, X.M.; Cui, L.Z.; Li, G.C. Exogenous expression of marine lectins DIFBL and SpRBL induces cancer cell apoptosis possibly through PRMT5-E2F-1 pathway. Sci. Rep. 2014, 4, 4505. [CrossRef] [PubMed]

34. Yang, X.Y.; Wu, L.Q.; Duan, X.M.; Cui, L.Z.; Luo, J.J.; Li, G.C. Adenovirus Carrying Gene Encoding Haliotis discus discus Sialic Acid Binding Lectin Induces Cancer Cell Apoptosis. Mar. Drugs 2014, 12, 3994-4004. [CrossRef] [PubMed]

35. Kirn, D.H.; Thorne, S.H. Targeted and armed oncolytic poxviruses: A novel multi-mechanistic therapeutic class for cancer. Nat. Rev. Cancer 2009, 9, 64-71. [CrossRef] [PubMed]

36. Bartlett, D.L.; Liu, Z.Q.; Sathaiah, M.; Ravindranathan, R.; Guo, Z.B.; He, Y.K.; Guo, Z.S. Oncolytic viruses as therapeutic cancer vaccines. Mol. Cancer 2013, 12, 103. [CrossRef] [PubMed]

37. Zhang, Q.; Yu, Y.A.; Wang, E.; Chen, N.; Dannel, R.L.; Munson, P.J.; Marincola, F.M.; Szalay, A.A. Eradication of solid human breast tumors in nude mice with an intravenously injected light-emitting oncolytic vaccinia virus. Cancer Res. 2007, 67, 10038-10046. [CrossRef] [PubMed]

38. Zhou, X.; Michal, J.J.; Zhang, L.F.; Ding, B.; Lunney, J.K.; Liu, B.; Jiang, Z.H. Interferon Induced IFIT Family Genes in Host Antiviral Defense. Int. J. Biol. Sci. 2013, 9, 200-208. [CrossRef] [PubMed]

39. Pachella, L.A.; Madsen, L.T.; Dains, J.E. The Toxicity and Benefit of Various Dosing Strategies for Interleukin-2 in Metastatic Melanoma and Renal Cell Carcinoma. J. Adv. Pract. Oncol. 2015, 6, 212-221. [PubMed]

40. Acquavella, N.; Kluger, H.; Rhee, J.; Farber, L.; Tara, H.; Ariyan, S.; Narayan, D.; Kelly, W.; Sznol, M. Toxicity and activity of a twice daily high-dose bolus interleukin 2 regimen in patients with metastatic melanoma and metastatic renal cell cancer. J. Immunother. 2008, 31, 569-576. [CrossRef] [PubMed] 